\title{
Bicentenario en Chile. La celebración de una laboriosa construcción política ${ }^{1}$
}

\author{
Sergio Grez Toso \\ Universidad de Chile \\ sergiogreztoso@gmail.com
}

Recibido: 15/06/2011

Aceptado: 01/08/2011

\begin{abstract}
Resumen
El autor de este artículo entrega desde una perspectiva histórica crítica algunas reflexiones sobre el sentido profundo de la conmemoración del Bicentenario en Chile. Para ello realiza un apretado recorrido por algunos hechos trascendentales de la historia de Chile de los últimos doscientos años, centrando su análisis en el sistema político republicano. El historiador Sergio Grez caracteriza el tipo de sociedad construida a lo largo del siglo XIX como oligárquica aunque con matices que le permiten diferenciar la República Conservadora de la Liberal. Enseguida evoca las grandes crisis económicas, sociales y políticas de las primeras décadas del siglo XX (período de maduración de la "cuestión social") para encontrar en su desenlace los elementos que permiten explicar el surgimiento del "Estado Providencia" o "Estado de compromiso". Se pasa revista al tratamiento "institucional" de los conflictos sociales y políticos, al modelo de sustitución de importaciones y su crisis en las décadas de 1950 y 1960, a la ampliación de las libertades democráticas entre 1958 y 1973, al ascenso de las luchas populares y la crisis sistémica que culminó con el golpe de Estado de 1973 y el colapso definitivo de la democracia liberal.

Finalmente, se caracteriza la nueva "ingeniería política" resultante de los compromisos de la transición a la democracia pactada entre las fuerzas sociales y políticas que sostenían a la dictadura del general Pinochet y el sector hegemónico (moderado) de las fuerzas opositoras, concluyendo con un breve contrapunto entre la situación del Chile actual y la imperante hacia 1910, a fin de responder a las interrogantes acerca del sentido de la conmemoración del Bicentenario.

Palabras clave: Bicentenario; Independencia; Chile; Sistema político; Cuestión social; Modelos de dominación
\end{abstract}

\section{Bicentenary in Chile. The celebration of a laborious political construction}

\begin{abstract}
The author of this article writes from a critical historical perspective some reflections on the deeper meaning of the commemoration of the Bicentenary in Chile. For that perperse he makes a tight tour of some important events of the history of Chile in the last two hundred years, focusing his analysis on the system Republican politician. The historian Sergio Grez characterizes the type of society built throughout the nineteenth century as oligarchic noticing the differences between the Liberal Republic of the Conservative Republic. Immediately after he evokes the great economic, social and political crisis, of the early twentieth century (period of maturation the "social question") to find its outcome by which to explain the emergence of "welfare state" or "State of commitment.". The he passes review of the institutional treatment of social and political conflicts, the model import substitution and its crisis in the 1950 and 1960, the extension democratic freedoms between 1958 and 1973, the rise of popular struggles and systemic crisis that culminated in the coup of 1973 and the definitive collapse of the liberal democracy.

Finally, he characterize the new "political engineering" resulting from the commitments of the transition to democracy agreed between the social and political forces that supported the dictatorship of General Pinochet and the dominant sector (moderate) of opposition forces, concluding with a brief
\end{abstract}


counterpoint between the situation in Chile current and prevailing in 1910, to respond to questions about the meaning the commemoration of the Bicentenary.

Key words: Bicentenary; Independence; Chile; Political System; Social Issues; domination models.

\section{Referencia normalizada}

Grez Toso, S. (2011). Bicentenario en Chile. La celebración de una laboriosa construcción política. Historia y Comunicación Social, Vol. 16, páginas 69-86.

Cuando el Estado de Chile empieza a conmemorar su Bicentenario, los intelectuales y los ciudadanos con conciencia crítica no pueden dejar de formularse una serie de interrogantes sobre el sentido profundo de estas celebraciones. Entre muchas otras: ¿Qué se está celebrando?, ¿qué tipo de país se ha construido durante estos doscientos años?, ¿de qué modo Chile ha llegado a ser lo que es?

Para hacerme cargo de algunas de estas preguntas me remontaré a los comienzos de la era republicana, para luego centrarme en el siglo XX.

Aunque la constitución del primer gobierno autónomo de la aristocracia criolla (el 18 de septiembre de 1810) que procuró llenar el vacío de poder dejado por la prisión del rey de España Fernando VII fue solo el inicio de un proceso que desembocaría ocho años más tarde en la Declaración de Independencia (12 de febrero de 1818) y en su consolidación en la batalla de Maipú (5 de abril de 1818), por razones de diversa índole que no es del caso evocar en esta ocasión, salvo el carácter puramente elitista (sin apoyo ni movilización popular) de la organización de la Primera Junta de Gobierno, lo cierto es que a partir de 1837, durante el primero de los decenios de gobiernos conservadores, el 18 de septiembre se constituyó en la fecha oficial de celebración del Estado y de la "chilenidad", quedando inscrita en la memoria de los habitantes del país como símbolo patriótico y de identidad nacional ${ }^{2}$.

Pero el sentimiento nacional no afloró espontáneamente en la población que quedó viviendo al interior de las imprecisas y muy cambiantes fronteras de la República de Chile en el siglo XIX. Durante las guerras de la Independencia (que tuvieron un verdadero carácter de guerra civil) la reacción mayoritaria de la gran masa popular fue el indiferentismo, la huida y la deserción (para escapar de las levas forzosas que practicaban ambos bandos, especialmente el ejército patriota), o su unión con montoneras realistas en la zona sur (después de las derrotas de las tropas leales al rey en la batalla de Maipú) ${ }^{3}$. Aunque a partir de la Reconquista española se observó cierto grado de adhesión a la causa independentista entre sectores del campesinado y del artesanado de la región central, es evidente que el patriotismo de la población "chilena" no surgió de un proceso "natural" o preexistente masivamente antes de que una facción de la clase dirigente criolla decidiera desplazar a la burocracia española, gobernarse por sí sola y echar las bases de un Estado nacional independiente. El historiador británico John Lynch al referirse a la actitud de los sectores populares frente al movimiento de emancipación política en Chile, ha sostenido con convicción que como estos "no tenían nada que ganar en la nación, carecían 
de sentido de nacionalidad"4. Lo que ha sido refrendado por numerosos estudios historiográficos realizados desde entonces, que han servido de base para que Julio Pinto y Verónica Valdivia en una reciente investigación acerca de la construcción social de la nación chilena entre 1810 y 1840 , concluyan que durante las guerras de la Independencia "el bajo pueblo no se demostró particularmente entusiasta frente a un proyecto que no le ofrecía beneficios muy tangibles, y sí en cambio sacrificios más que evidentes" 5 . El conocimiento historiográfico acumulado permite afirmar con bastante certeza que el "bajo pueblo" fue incorporado a estas luchas más por la represión y coacción que por convicción o persuasión política, y también que la "soberanía popular" condujo a lo que la pareja de historiadores recién citados define como una "ficción democrática" ya que "en la idealidad el mundo político se ampliaba, aunque en realidad una gran mayoría de la población no cumpliera con las condiciones para ser ciudadanos activos. En esas condiciones, el poder real seguía radicando en los grupos dirigentes, los que asumían los intereses de la sociedad toda, levantándose como encarnación simbólica de dicha soberanía"6.

Empero, es preciso constatar que en cuestión de algunas décadas, gracias a la temprana conformación de lo que el historiador conservador Alberto Edwards denominó el "Estado en forma", al eco del ideario republicano entre algunos estratos populares como el artesanado urbano y a la implementación de una estrategia de disciplinamiento social, en un contexto de cierta homogeneidad geográfica y cultural en el llamado "Chile histórico" o "Chile central" 8, fue surgiendo entre vastos sectores de la población la lealtad patriótica anhelada por la clase dirigente. Cabe destacar que los mecanismos de disciplinamiento de los sectores populares fueron muy variados. Entre los puramente coercitivos destacaban los trabajos forzados, las penas de azotes, los carros rodantes como prisión ambulante para los condenados a trabajos forzados, el sistema de papeletas para controlar los desplazamientos de los peones mineros y la instalación de jefes militares sobre la jurisdicción de los principales yacimientos mineros del Norte Chico. Otros eran de tipo más "pedagógico" como la celebración de ciertas festividades nacionales, la difusión de los símbolos "patrios" (bandera, escudo e himno nacional), y la utilización en una perspectiva nacionalista del poder ya legitimado de la Iglesia Católica. También existieron dispositivos como el servicio obligatorio en las filas de la Guardia Nacional, que combinaban coerción y "educación patriótica". La acción convergente de estos mecanismos dio los resultados esperados por la elite dirigente. Cuando en la década de 1880 el Estado de Chile culminó su expansión conquistando el territorio mapuche de la Araucanía, la provincia peruana de Tarapacá y la provincia boliviana de Antofagasta, el sentimiento nacionalista ya era una realidad indesmentible en la mayor parte de la población, como pudo apreciarse en la Guerra del Pacífico, cuando los enrolados voluntariamente en las Fuerzas Armadas chilenas superaron a los reclutas forzados ${ }^{10}$.

A través de un siglo de guerras internas y externas, sucedidas de períodos de refundación, reacomodo y negociación regulada entre sus facciones, la clase dominante chilena logró consolidar uno de los Estados nacionales más poderosos de Sudamérica. Luego de las guerras de la Independencia, transcurrió un período de 
variados ensayos políticos que cubrieron desde el cesarismo hasta el liberalismo doctrinario más radical. Durante la década de 1820 los representantes de esta tendencia (los llamados "pipiolos"), que no rechazaban teóricamente la posibilidad de hacer de los sectores populares actores políticos con derechos y deberes ciudadanos, intentaron echar las bases de una comunidad nacional más inclusiva e integrada, especialmente a partir de la Constitución liberal de 1828, en base a los principios de libertad individual, rechazo al despotismo y la "anarquía", "preferencia por instancias colegiadas como los congresos, las representaciones regionales y provinciales, libertad de expresión y derechos civiles, valoración del sufragio, aunque censitario, aspirando a la construcción futura de un pueblo real capaz de asumir el destino nacional en sus manos" 11 . Sin embargo, estas medidas sumadas al relajamiento de los controles sociales que produjeron las guerras de Independencia y las disputas en el seno de la elite, terminaron exacerbando la paciencia de la clase dominante de la región central cuya cabecera estaba en la ciudad de Santiago. El desfase entre la elite gobernante -que representaba aspiraciones liberales e incluso democráticas- y las conservadoras clases dominantes en el terreno de la propiedad, se hizo evidente ${ }^{12}$. Entonces una vigorosa reacción de estas últimas puso término, mediante una breve guerra civil, a las veleidades liberalizadoras de los ideólogos más avanzados de la clase política y de las provincias extremas (Copiapó y Concepción) que luchaban por zafarse de la dominación centralista santiaguina ${ }^{13}$. El triunfo conservador en la batalla de Lircay fue la base del poder constituyente que en 1833 dio sustento legal a la dominación omnímoda y excluyente de esa misma facción de la elite a través de la Constitución de $1833^{14}$.

Este régimen político -cuyo inspirador y principal constructor fue el ministro Diego Portales- engendró nuevas guerras civiles, en 1851 y 1859, que lo debilitaron considerablemente. A pesar de las derrotas militares de los contestatarios, a comienzos de la década de 1860 se dio inicio a una transición política que apuntaba a la constitución de lo que Tomás Moulián ha caracterizado como un "estado de compromiso oligárquico" y que culminó, luego de otra guerra civil, en 1891, en la instauración de un sistema regulado y competitivo de "democracia oligárquica" con cierta capacidad de integración y cooptación de ciertas expresiones políticas populares (como el Partido Democrático). Del sistema político oligárquico profundamente excluyente imperante durante la República Conservadora (18301860) se pasó -luego de dos guerras civiles y un complejo proceso de negociaciones y apertura política- a un sistema igualmente oligárquico, pero abierto a todas las facciones de la clase dominante, crecientemente competitivo y capaz de practicar una pequeña apertura en dirección de algunos estratos del mundo popular mediante la supresión del censo o requisito de riqueza para acceder a la "ciudadanía activa", dejando como única exigencia el saber leer y escribir, lo que equivalía al establecimiento del sufragio universal masculino, aunque de manera muy acotada dado las altas tasas de analfabetismo imperantes en el mundo popular. El resultado fue, en el decir de Moulián, una "democracia elitaria de negociación", que entre 1861 y 1890 efectuó pacíficamente reformas liberales como la recién mencionada además de la reforma de la ley de imprentas y el voto de las llamadas leyes laicas (de registro civil, 
matrimonio civil y cementerios laicos). No obstante, el acto final de este proceso fue de una violencia superior a lo vivido en los conflictos intestinos anteriores. En 1891, nueva guerra civil mediante ${ }^{15}$, el presidencialismo "portaleano" fue completamente anulado y sustituido por una forma de negociación entre las elites políticas -el parlamentarismo- que hasta 1924 aseguró a las distintas facciones oligárquicas un reparto pacífico de las cuotas de poder y de la riqueza salitrera a través del control colectivo y regulado del aparato estatal ${ }^{16}$.

Al cabo de un siglo de guerras civiles, guerras externas, expansión territorial, negociaciones y apertura política controlada, en medio de la bonanza económica que el salitre aportó al Fisco y a la oligarquía, el Estado de Chile se aprestó a celebrar con gran pompa su primer Centenario. Pero desde mucho antes de 1910 la celebración estuvo opacada por la irrupción sangrienta de la "cuestión social": la miseria popular en los campos y ciudades, la insalubridad de los ranchos, conventillos y "cuartos redondos", la proliferación de mortíferas enfermedades y epidemias, las altísimas tasas de mortalidad, especialmente infantil (las más altas del mundo occidental), la alarmante expansión del alcoholismo y la prostitución, la cesantía y la emergencia de un movimiento obrero y popular de orientación clasista que abrazaba las banderas del anarquismo y del socialismo, eran los síntomas más evidentes de un profundo drama que desgarraba a la sociedad chilena ${ }^{17}$. Y por sobre todo, impactaba a los contemporáneos, especialmente extranjeros, la gran desigualdad social, descrita en 1910 por el más afamado de los ensayistas chilenos del Centenario, como "el contraste entre la gente adinerada y la clase trabajadora; porque en Chile hay solo dos clases sociales, ricos y pobres, esto es, explotadores y explotados; no existe la clase media: los que no somos ricos ni menesterosos y aparentemente formamos el estado llano, somos gente de tránsito, salida del campo de los explotados y en camino para el de los opulentos" 18 .

El régimen parlamentario -sostiene Gabriel Salazar- no había entrado en escena para resolver el conflicto económico-social "sino, más específicamente, para asegurar la sobrevida de las elites mercantiles (portalianas) ante la agudización de la crisis y tras el colapso de la dictadura constitucional que esas elites habían establecido en 1833"19. De aquí que el parlamentarismo, pese a la modernización que involucraba, no inauguró siquiera una consistente política desarrollista sino tímidos ajustes económico-nacionalistas y dramáticas reediciones de la política represiva contra las masas ${ }^{20}$. Otros historiadores han aseverado que la elite de la República Parlamentaria tampoco se preocupó mayormente por incorporar a los trabajadores en un sistema consensual, quizá porque contaba con la sólida base electoral de los campesinos. Ello explicaría que frente al creciente conflicto social, la reacción de esa elite fuera muy dura, sin intentar distinguir y negociar con los elementos más conciliadores del mundo popular ${ }^{21}$. Un ciclo de luctuosas masacres obreras entre 1903 y 1907 fue la respuesta del Estado y la clase dominante ante una "cuestión social" cuya existencia era negada incluso por políticos "progresistas" como el patriarca radical Enrique Mac-Iver ${ }^{22}$.

No obstante, en vísperas del primer Centenario de la Independencia nacional, las elites políticas e intelectuales comenzaron a intuir que era necesario una reingeniería 
política, pero ya no solo en las fórmulas para regular el conflicto y repartir el poder entre distintas facciones oligárquicas sino, sobre todo, para contener, morigerar y canalizar adecuadamente el descontento proveniente de las clases populares. Luego de la masacre de la escuela Santa María de Iquique (1907), la clase política percibió más claramente la necesidad de un cambio ${ }^{23}$. El proceso que llevó a la adopción de la legislación social en 1924 y a la Constitución de 1925 como bases del "Estado de compromiso" y "Estado de bienestar a la chilena", fue largo y sinuoso. La tardía decisión de las elites políticas de la clase dominante explica, sin duda, la combatividad y organización de los trabajadores chilenos desde el siglo XIX y su precoz conversión en "clase", en el sentido más clásico del término, lo que les daría un perfil singular en Latinoamérica. Este fenómeno ha sido subrayado por el historiador trasandino Luis Alberto Romero, quien ha afirmado que, "a diferencia de la Argentina, por ejemplo, los trabajadores chilenos casi no transitaron la vía de la negociación, animaron centrales obreras politizadas y fuertemente enfrentadas con el Estado y dieron vida a partidos de tradición marxista tan vigorosos que en el siglo XX se convirtieron en alternativas de poder"24. Solo nuevas convulsiones sociales y políticas, recurrentes crisis salitreras a partir de 1914, grandes movilizaciones populares (como las de 1918 y 1919), nuevas masacres obreras (entre 1919 y 1921) y la enérgica irrupción de los militares en el escenario político terminaron por convencer a los representantes de la elite política que era inevitable un rediseño estratégico.

En la nueva fórmula ciertas concesiones a los trabajadores, la cooptación de sus dirigentes, las leyes sociales, los mecanismos de conciliación y arbitraje para impedir o resolver las huelgas, el diálogo y la seducción jugarían un rol más destacado que la pura represión. A cambio de ello, los trabajadores deberían comprometerse a despolitizar sus organismos gremiales, aceptar los mecanismos institucionalizados, dejar la huelga solo como último recurso, reconocer el orden sociopolítico y expresarse a través de sus canales institucionalizados. Las leyes de contrato de trabajo para obreros y empleados, de sindicatos y cooperativas, de Seguridad Social (seguros de enfermedad, invalidez y accidentes del trabajo), de conciliación y arbitraje, de prohibición del trabajo de los menores y de creación de la Dirección General del Trabajo, aprobadas a mediados de la década de 1920, fueron el paso decisivo de un proceso iniciado casi dos décadas antes cuando empezaron a discutirse y a votarse las primeras -muy tímidas e imperfectas- leyes sociales ${ }^{25}$. La legislación social fue, como la ha definido con toda propiedad Juan Carlos Yáñez, "el último mecanismo de control del mercado laboral, cuando ya no eran efectivas las formas tradicionales de disciplinamiento de la mano de obra" 26 . La historiografía chilena ha conceptualizado los cambios en las funciones del Estado que se consumaron durante esa década como un paso del "Estado oligárquico" u "oligárquico liberal" a los comienzos del "Estado asistencial" "intervencionista" o "de compromiso". Sin negar esas características en las nuevas funciones del Estado, pero introduciendo matices muy sugerentes, el historiador Enrique Fernández Darraz ha formulado la hipótesis de una extensión del "Estado excluyente", a través de su expansión territorial y social que implicó asumir nuevas funciones y una nueva relación con amplios sectores de la población, especialmente los sectores populares, que hasta entonces habían vivido 
prácticamente en sus márgenes. La expansión del "Estado excluyente" habría significado acercarlo a los trabajadores que se convirtieron en objetos positivos de las prácticas políticas, administrativas y legales de la elite. Este proceso habría constituido -según Fernández Darraz- una paradoja oligárquica, ya que al aproximar el "Estado excluyente" a los obreros, estos lo vieron como una buena posibilidad de solución de sus propios problemas, socavando las bases del monopolio político de los grupos oligárquicos 27 .

Cualquiera sea la interpretación que se suscriba respecto de estos fenómenos, es incuestionable que el talón de Aquiles del nuevo sistema siguió siendo el orden socioeconómico ya que hasta bien avanzada la década de 1930, tal como afirma Gabriel Salazar, la nueva democracia liberal no dio pasos para la construcción de un "Estado Empresarial Fabril" ni uno "Social Benefactor" sino un nuevo sistema político de equilibrio que permitiera capear una crisis centenaria, lo que explica las altas y crónicas dosis de violencia estatal, en particular contra los movimientos populares cuando estos rebasaban los límites impuestos por el Código del Trabajo28.

Con todo, luego de una década de gravísima crisis económica, especialmente durante los años de la Gran Depresión, y de gran inestabilidad política, en que se vivió el ascenso y caída de la dictadura populista del general Carlos Ibáñez del Campo, la sucesión de varios gobiernos de corta duración incluyendo una brevísima "República Socialista" resultante de un putsch militar populista que gozó de cierto apoyo de masas, y otros dramáticos acontecimientos como un amotinamiento de la marinería y el levantamiento conjunto de mapuches y campesinos pobres chilenos en Ranquil (Alto Bío-Bío), el "Estado de compromiso" logró echar bases y gozar de cierta estabilidad 29 . La legislación laboral empezó a hacerse efectiva y desde la llegada del Frente Popular al gobierno en 1938 se desarrolló una estrategia de sustitución de importaciones. Las diversas fórmulas frentepopulistas implementadas entre 1938 y 1947 contribuyeron notablemente al logro de esta estabilidad y gobernabilidad sistémica, trazando una ruta que se prolongaría durante varias décadas, con algunos quiebres, discontinuidades y reformulaciones, más allá de la experiencia original del Frente Popular. Desde mediados de la década de los años 30 y hasta inicios de los 70, el movimiento obrero y popular marchó mayoritariamente por la vía institucional, parlamentaria y gradualista escogida por los partidos mayoritarios de la izquierda. Durante los años de aplicación de la política de Frente Popular, a cambio del impulso a la industrialización dentro del sistema capitalista, la ampliación de las libertades civiles y políticas, el perfeccionamiento de la legislación social $\mathrm{y}$ algunos beneficios materiales para los sectores populares urbanos, la izquierda socialista y comunista optó por sacrificar los intereses del campesinado (posponiendo indefinidamente la reforma agraria y el derecho a la sindicalización de los trabajadores agrícolas), y reafirmó el tránsito exclusivo por la institucionalidad y el respeto irrestricto de los intereses de la "burguesía nacional", que recibió un fuerte apoyo estatal a través de los planes de industrialización de la coalición gobernante compuesta esencialmente por radicales, socialistas y comunistas ${ }^{30}$.

El compromiso parecía funcionar. La construcción de una nación más integrada asomó más posible que nunca. Pero antes de una década esta política de colabora- 
ción de clases empezó a hacer agua y, a fin de cuentas, el balance de la experiencia frente populista fue magro. Como bien acota Tomás Moulian, "esas coaliciones promovieron el crecimiento industrial pero no produjeron una 'revolución capitalista', [y] generaron una mayor democratización de oportunidades pero no una "revolución democrática" ${ }^{31}$. Dos factores pesaron decididamente en su contra: el incipiente agotamiento del modelo de sustitución de importaciones, que por ser dependiente de la maquinaria y la tecnología importada no logró generar un círculo virtuoso capaz de arrastrar al conjunto de la economía chilena para sacarla de su endémico subdesarrollo, y el estallido de la "Guerra Fría" entre Estados Unidos y la Unión Soviética y sus respectivos aliados, clausurándose la "Gran Alianza" que estas potencias habían contraído durante la Segunda Guerra Mundial para hacer frente al nazi-fascismo. La ilegalización del Partido Comunista de Chile y la persecución de sus militantes y de los dirigentes del movimiento obrero de su área de influencia, provocada por la aplicación de la "Ley de Defensa de la Democracia" restringió sustantivamente el consenso social y político durante una década ${ }^{32}$. El "Estado de compromiso" pareció definitivamente arruinado entre 1948 y 1952.

Sin embargo, la elección de Carlos Ibáñez del Campo a la Presidencia de la República en base a un programa populista y de saneamiento moral, significó una transición hacia una reedición del pacto social y político que había asegurado la gobernabilidad hasta fines de la década anterior. La derogación de la ley que proscribía las actividades comunistas y algunas reformas destinadas a hacer más transparente los procesos electorales ${ }^{33}$ permitieron que entre 1958 y 1973 la democracia chilena alcanzara, por primera vez, standares más adecuados. Esa fue la "época de oro" del sistema democrático en Chile, período que ha nublado la visión de muchos analistas que han proyectado retrospectivamente el clima resultante de la democratización política y social de estos lustros hacia el resto del siglo XX e incluso hasta el siglo XIX.

Pero nuevamente el alabado sistema político chileno mostró sus grandes debilidades. La crisis económica golpeaba a la mayoría de la población bajo la forma de una inflación crónica y elevadas tasas de desocupación. Entonces, a medida que los sectores populares hicieron uso de los espacios democráticos y de las libertades conquistadas a lo largo de un siglo de luchas sociales, el orden político comenzó a crujir. Durante la década de 1960, las administraciones de Jorge Alessandri y Eduardo Frei Montalva hicieron frente a un creciente malestar popular utilizando cada vez más frecuentemente la represión. Las masacres de la población José María Caro de Santiago (1962), del mineral de El Salvador (1966), y de Pampa Irigoin en Puerto Montt (1969)34, junto a la irrupción militar del "tacnazo" (1969) pusieron en evidencia la fragilidad de la institucionalidad consensuada entre las clases dominantes y los representantes políticos de los trabajadores. El sistema institucional respondía cada vez más mal al ascenso de las luchas populares que desde 1967 se expandieron y generalizaron considerablemente. Sistema político fragilizado, inflación crónica, creciente efervescencia social en un panorama internacional marcado por grandes tensiones entre la Unión Soviética y Estados Unidos y el ascenso de los movimientos de liberación nacional (especialmente africanos) y de los movimientos 
revolucionarios anticapitalistas en el mundo occidental y antiburocráticos en los países de Europa Oriental, fueron los principales elementos del contexto en que se enmarcó la victoria electoral que llevó a Salvador Allende a la Presidencia de la República como abanderado de una coalición política -la Unidad Popular- que se proponía iniciar la transición al socialismo a través de la vía pacífica institucional.

El sistema político chileno mostró su máxima elasticidad entre septiembre de 1970 y julio de 1971, esto es, desde la elección de Allende hasta la nacionalización del cobre aprobada unánimemente por el Congreso Nacional. Sin embargo, desde mediados de 1971 el conflicto social y político se agudizó progresivamente hasta alcanzar niveles sin precedentes desde la guerra civil de 1891. El centro político fue absorbido por la derecha golpista y se sumó a su estrategia. Los mecanismos institucionales fueron incapaces de regular el conflicto. Pero esta vez no se trató de una disputa en el seno de las elites de la clase dirigente sino de un enfrentamiento social y político que tuvo las características de una lucha de clases que dividió a la sociedad chilena en dos bloques más o menos equivalentes. De un lado, el conjunto de la burguesía y de otros sectores que marcharon bajo sus banderas: terratenientes, gran burguesía comercial e industrial, la mayoría de las clases medias y algunas franjas del mundo popular, especialmente aristocracia obrera. En la orilla opuesta, un combativo conglomerado popular compuesto por la mayoría de la clase obrera y del campesinado, más significativos sectores del estudiantado, de la intelectualidad y de las clases medias asalariadas. La frágil construcción política democrática colapsó producto de este enfrentamiento y de la intervención del imperialismo norteamericano ${ }^{35}$.

La institucionalidad democrática mostró sus límites cuando los sectores populares intentaron hacer realidad sus sueños de justicia social mediante el cumplimiento del programa ofrecido por los partidos políticos de izquierda. El gobierno de la Unidad Popular ha sido considerado retrospectivamente por muchos analistas como una experiencia condenada al fracaso. No obstante, habría que preguntarse si acaso esa no fue la última oportunidad en el siglo XX de haber echado los cimientos de una nación integrada en base a un compromiso social progresista. Pero las clases dominantes no tenían ni la disposición, ni la madurez, ni la sensibilidad para ser parte de un proceso donde el conflicto no estaba excluido, pero uno de cuyos resultados podría haber sido una nación más inclusiva. La dictadura terrorista de Pinochet fue el medio escogido por estos sectores y el imperialismo para quebrar la espina dorsal del movimiento obrero y popular y clausurar la posibilidad de un juego de alternativas de proyectos de sociedad.

Una nueva ingeniería política se gestó en la fase de declive del régimen de Pinochet como resultado de las transacciones entre los representantes de la dictadura y de la oposición moderada conformada por la Democracia Cristiana y buena parte de la dirigencia de izquierda que había sostenido la experiencia de la Unidad Popular. De ello resultó un sistema político de "democracia protegida" o restringida, con más limitantes, cortapisas y restricciones que la que existió entre 1958 y 1973 y con mucho menos admisibilidad de la disidencia y del conflicto social. Por ello, en nuestros días los movimientos de protesta social son sistemáticamente negados en su legitimidad y reprimidos por el Estado ${ }^{36}$. 
La gobernabilidad y estabilidad de este nuevo orden se basó durante veinte años en la contención por parte de la coalición gobernante (la Concertación de Partidos por la Democracia) de las demandas sociales mediante una hábil política de desmovilización popular, práctica del clientelismo sectorial, correctivos "sociales" al modelo neoliberal y represión de los movimientos de protesta social cuando estos desbordan los estrechos márgenes de tolerancia existentes en el Chile postdictatorial. La política aplicada ha sido descrita con precisión sintética por el sociólogo Tomás Moulian como la consagración por el bloque concertacionista de "la limitación del Estado a roles reguladores, un amplio espacio para la iniciativa privada y la definición de los empresarios como los sujetos históricos de la nueva sociedad"37. El contrapunto de la diversificación de las exportaciones, las tasas de crecimiento económico sostenidas, la alta inversión extranjera y el reconocimiento internacional de Chile como un país modelo es la mercantilización total de la previsión y de las empresas de "servicios públicos" (agua, electricidad, gas y teléfono), "una amplia mercantilización de la educación y de la salud y la total transformación de la fuerza de trabajo en una mercancía como cualquier otra, cuyo precio no es la resultante de la capacidad de organización y de fuerza política si no es colocada por un mercado que demanda cada vez más flexibilidad" ${ }^{38}$. A lo que habría que agregar la irreductible mantención de la desigualdad social, que ubica a Chile -a pesar del progreso económico- como uno de los países con peor distribución del ingreso del mundo ${ }^{39}$.

La asimilación de la ideología neoliberal por parte de los antiguos opositores a Pinochet que asumieron el gobierno a partir de 1990, su política de coadministración con la Derecha clásica y la legitimación por parte de la Concertación Democrática del modelo neoliberal y del gran empresariado como el principal sujeto histórico, terminaron por borrar las diferencias entre los bloques hegemónicos en la conciencia de vastos sectores de la población. Un resultado de esta política ha sido la elección a la Presidencia de la República de uno de los principales magnates chilenos en brazos de la alianza de derecha tradicional, que por primera vez en más de cincuenta años logró ungir a uno de los suyos en la máxima magistratura de la República por medio del sufragio universal ${ }^{40}$.

En este contexto, el Bicentenario ofrece algunas similitudes fundamentales con la situación imperante en el Centenario. Al igual que entonces, la economía chilena no logra escapar al patrón primario exportador y el Estado y las clases dominantes gozan de una prosperidad sin par. Aunque en la actualidad los niveles de pobreza son muy inferiores a los que existían en 1910 y los índices de calidad de vida de la mayoría de la población son muy superiores a los de hace un siglo, la desigualdad social se mantiene inalterable y se cierne como una sombra sobre la tan anunciada unidad nacional. A decir verdad, fuera del ámbito simbólico, la inmensa mayoría de la población del Estado nación República de Chile no tiene razones objetivas para celebrar los doscientos años de una arquitectura política resultante de imposiciones de la fuerza militar, conciliábulos y transacciones de las cúpulas políticas sin participación significativa de la ciudadanía, salvo en situaciones excepcionales cuya repetición desea ser descartada a toda costa por la clase política ${ }^{41}$. El Bicentenario es, por excelencia, la festividad de los principales beneficiarios del sistema económico 
y político: las clases dominantes y los administradores del sistema político.

La gran masa popular será, sin duda, convocada y se sumará al jolgorio inducido por los medios de comunicación y los aparatos de propaganda del Estado y de otras instituciones interesadas en la operación política denominada Bicentenario. Cuando hace cien años Chile se aprestaba a festejar el primer Centenario del Estado nación, el más destacado dirigente obrero de aquella época, Luis Emilio Recabarren nos dejó una descripción de una situación que veremos repetirse en nuestros días:

"Pero, decidme la verdad, ¿en qué consiste la participación del pueblo en todas las grandes festividades? ¡Ah!, vaciláis para confesaros la verdad! La mayor cuota que el pueblo aporta en estas festividades consiste en embriagarse al compás del canto y en embriagarse hasta el embrutecimiento que los conduce a todas las locuras.

Pero esa embriaguez es un progreso. Si ella proporciona al pueblo abundancia de miserias en cambio a los productores de licor y a los intermediarios les produce torrentes de oro ganado a costa de la corrupción. ¡Verdad que esto es muy triste. Es por todo esto que he dicho que yo no siento entusiasmo espontáneo para festejar el centenario de la República que ningún bien de verdadero valor moral ha producido para nosotros. Que se regocijen y se entusiasmen los que han aprovechado y aprovecharán del progreso y que sean siempre felices son mis votos" 42 .

\section{A modo de conclusión}

La reflexión de Recabarren en el Centenario guarda mucha validez en el Chile actual. Sus votos para que en el segundo siglo de vida de esta República fuera una era de verdaderos progresos morales que aseguraran el triunfo de la igualdad social, no surtieron efecto.

A pesar del discurso oficial del éxito económico y de la modernización, aún no se encuentran las bases materiales, culturales, institucionales y políticas para lograr una nación más inclusiva. El país construido en el siglo XX (y en lo que va corrido del siglo XXI) se parece en muchos aspectos al del siglo XIX. La nación sigue viviendo un porfiado desgarramiento estructural. Chile está muy lejos de alcanzar niveles aceptables de cohesión social ${ }^{43}$. En vez de la democracia oligárquica de comienzos del siglo XX, existe una democracia liberal de baja intensidad que convoca a sus ciudadanos solo para legitimar decisiones tomadas en un marco de restricciones interiorizadas por el ejercicio del poder tutelado. La apatía y rechazo de la población chilena a la política institucional y los políticos profesionales, expresada en todas las encuestas de opinión pública y en los millones de ciudadanos no inscritos en los registros electorales, se explica esencialmente porque las soluciones a los problemas económicos y sociales han sido despojadas de su contenido político, presentándose como eminentemente técnicas ya que los fines de la sociedad no pueden ser cuestionados o discutidos ${ }^{44}$. Los movimientos sociales (exceptuando el movimiento nacional mapuche) aún son débiles y dispersos, no son solidarios entre sí y su nivel de politización es, por regla general, muy bajo ${ }^{45}$. Solo las campañas electorales provocan efímera y débilmente la ilusión de que la política vuelve por sus fueros a nivel de la masa ciudadana. Pero es solo un espejismo. Los poderes fácticos 
y los administradores del sistema velan porque todo se mantenga así. Una vez más la ingeniería política parece haber dado en el clavo.

Ya van veinte años de estabilidad de la nueva arquitectura política, lo que hace proclamar a muchos analistas el éxito de esta laboriosa fórmula. Si bien es cierto que desde 1925 Chile no conoció un período tan largo sin intervención militar, sin dictadura o sin leyes de excepción que declaren ilegales a ciertas organizaciones políticas, las dos últimas décadas de democracia tutelada de baja intensidad representan apenas dos tercios del período que medió entre 1860 y la guerra civil de 1891 y un porcentaje aún menor del que transcurrió entre el desenlace de ese conflicto y 1924, cuando la fuerza armada nuevamente dirimió la disputa política. La actual construcción política aún no ha pasado por pruebas muy difíciles. Sus principales beneficiarios se aprestan a festejar tranquilos el Bicentenario.

\section{Notas}

1 Una versión preliminar de este texto fue presentada en Seminario "Debates críticos sobre el Chile del Bicentenario", organizado por el Subprograma Domeyko Transversal, el Programa de Investigación Domeyko y el Instituto de la Comunicación e Imagen de la Universidad de Chile, Santiago, Instituto de la Comunicación e Imagen, 4 de noviembre de 2009. La presente versión sirvió de base para una ponencia presentada en el Colloque International Interdisciplinaire Amérique Latine/Caraïbes et Europe organizado por el Centre d'Études des Relations entre l'Union Européenne et l'Amérique Latine (CERCAL) de la Université Libre de Bruxelles, Bruselas, Palais d'Egmont II, 11 de febrero de 2010

2 Paulina Peralta, ;Chile tiene fiesta! El origen del 18 de septiembre (1810-1837), Santiago, Lom Ediciones, 2007.

3 Véase entre otros, Mario Valdés Urrutia, "La deserción en el ejército patriota durante la guerra de Independencia de Chile: 1813-1818. Notas para su comprensión", en Revista Chilena de Historia y Geografía, No 164, Santiago, 1998, págs. 103-126; Gladys Varela y Carla Manara, "En un mundo de frontera. La guerrilla realista-chilena en territorio pehuenche", en Revista de Estudios Trasandinos, Nº4, Santiago, julio de 2000, págs. 341-363 y "Tiempos de transición en las fronteras surandinas: de la Colonia a la República, en Susana Bandieri, Cruzando la Cordillera... La frontera argentino-chilena como espacio social, Neuquén, Universidad Nacional del Comahue, 2002, págs. 31-63; Ana María Contador, Bandidaje y guerrilla. Los Pincheira: un caso de bandidaje social 1817-1832, Santiago, Bravo y Allende, 1998; Leonardo León, "Reclutas forzados y desertores de la Patria: el bajo pueblo chilena en la Guerra de la Independencia, 1810-1814", en Historia, №35, Santiago, 2002, págs. 31-63; "La otra guerra de la Independencia: el éxodo patriota de Penco, 1817-1818", en Estudios Coloniales, N4, Santiago, 2005; Sergio Grez Toso, De la "regeneración del pueblo" a la huelga general. Génesis y evolución histórica del movimiento popular en Chile (1810-1890), Santiago, RIL Editores, 2007, 2ª ed., págs. 189-209.

4 John Lynch, Las revoluciones hispanoamericanas 1810-1826, Barcelona, Editorial Ariel, 1926, pág. 149; Julio Pinto Vallejos y Verónica Valdivia Ortiz de Zárate, 
¿Chilenos todos? La construcción social de la nación (1810-1840), Santiago, Lom Ediciones, 2009, págs. 120-144.

5 Pinto y Valdivia, op. cit., pág. 334. El concepto de "ficción democrática" ha sido tomado por estos historiadores de François-Xavier Guerra, Modernidad e independencia, México, Mapfre/FCE, 1992. Los trabajos sobre la actitud popular en el proceso de emancipación política están citados en la nota 2. Pinto y Valdivia, op. cit., pág. 81 .

6 Pinto y Valdivia, op. cit., pág. 81.

7 Alberto Edwards, La Fronda Aristocrática en Chile, Santiago, Imprenta Nacional, 1928.

8 El territorio comprendido desde la zona de Copiapó hasta el río Bío-Bío.

9 Véase, entre otros: Grez, op. cit., págs. 233-248; María Angélica Illanes, “Azote, salario y ley. Disciplinamiento de la mano de obra en la minería de Atacama (18171850)", en Proposiciones, N¹9, Santiago, julio de 1990, págs. 90-123; Marco Antonio León, "Entre el espectáculo y el escarmiento: el presidio ambulante en Chile (1836-1847), en Mapocho, N43, Santiago, primer semestre de 1998, págs. 183-209; Peralta, passim; Pinto y Valdivia, op. cit., págs. 144-151, 195-205, 227-240 y 279297.

10 Sobre la reacción patriótica de vastos sectores populares chilenos durante la Guerra del Pacífico, véase Grez, op. cit., págs. 565-570.

11 Pinto y Valdivia, op. cit., pág. 157.

12 Tomás Moulián, Contradicciones del desarrollo político chileno 1920-1990, Santiago, Lom Ediciones, 2008, págs. 10 y 11. Este autor ha subrayado el desencuentro existente entre la clase política (liberal) predominante durante la década de 1820 y la clase de los grandes propietarios (conservadora), lo que convertía a la primera en una intelectualidad "inorgánica", sin base material de clases, "desfasada de la oligarquía terrateniente que aspiraba al nivel político a reproducir el orden paternalista aristocrático de la hacienda, en cuanto formadora de la matriz cultural". Ibid.

13 El historiador que mayor énfasis ha puesto en la posibilidad de construir una comunidad política más incluyente entre 1823 y 1829 ha sido Gabriel Salazar Vergara, Construcción de Estado en Chile (1800-1860). Democracia de los "pueblos". Militarismo ciudadano. Golpismo oligárquico, Santiago, Editorial Sudamericana, 2005. Una visión más matizada en Pinto y Valdivia, op. cit., págs. 159-205.

14 Salazar, Construcción de Estado..., op. cit., págs. 322-327. Una visión distinta sobre el régimen político conservador, interpretado como "una fusión del legado autoritario del imperio español (incluidas sus apariencias) con buena parte de la sustancia del constitucionalismo republicano liberal", se encuentra en la obra del historiador británico Simon Collier, Chile. La construcción de una república 1830-1865. Política e ideas, Santiago, Ediciones de la Universidad Católica de Chile, 2008, $2^{a}$ ed., págs. 57-83.

15 La bibliografía sobre la guerra civil de 1891 es muy abundante. Entre las numerosas publicaciones que aparecieron con motivo del centenario de dicho conflicto destacan, 
por la variedad de enfoques y puntos de vista, tres obras colectivas: Dimensión Histórica de Chile, Nº8, Santiago, Universidad Metropolitana de Ciencias de la Educación, 1991; Diversos autores, La época de Balmaceda, Santiago, Dirección de Bibliotecas, Archivos y Museos - Centro de Investigaciones Diego Barros Arana, 1992; Luis Ortega (editor), La guerra civil de 1891. Cien años hoy, Santiago, Departamento de Historia Universidad de Santiago de Chile, 1993.

16 Moulián, op. cit., págs. 12-19. Cf. Julio Heise González, El período parlamentario 1861-1925, Tomo II Democracia y gobierno representativo en el período parlamentario, Santiago, Editorial Universitaria, 1982, especialmente págs. 23-112. Un relato y análisis pormenorizado de la crisis de la República Conservadora y de la transición hacia el régimen político liberal (1851-1864) fue desarrollado por Simon Collier, op. cit., págs. 249-317. Desde una perspectiva más crítica, Gabriel Salazar ha señalado que el "sistema portaleano" (1830-1891) "ha sido el único régimen que incubó y experimentó varias guerras civiles: una en su origen (1829-30), dos en su apogeo (1851 y 1859) y una en su declinación (1891). También ha sido el único que involucró al país en tres guerras exteriores”. Gabriel Salazar, La violencia política popular en las “Grandes Alamedas". La violencia en Chile 1947-1987 (Una perspectiva histórico popular), Santiago, Lom Ediciones, 2006, 2ª ed., pág. 70.

17 Sobre la "cuestión social" y sus consecuencias, véase entre otros, James O. Morris, Las élites, los intelectuales y el consenso. Estudios de la cuestión social y el sistema de relaciones industriales en Chile, Santiago, Editorial del Pacífico, 1967; Gonzalo Vial Correa, Historia de Chile (1891-1973), Santiago, Editorial Santillana del Pacífico, 1981, vol. I, tomo II, págs. 495-551 y 745-782; Ximena Cruzat y Ana Tironi, "El pensamiento frente a la cuestión social en Chile", en Mario Berríos et al., El pensamiento en Chile 1830-1910, Santiago, Nuestra América Ediciones, 1987; Julio Pinto Vallejos, "La caldera del desierto. Los trabajadores del guano y los inicios de la cuestión social”, en Proposiciones, N¹9, Santiago, julio de 1990, págs. 123-141 y “¿Cuestión social o cuestión política? La lenta politización de la sociedad popular tarapaqueña hacia el fin de siglo (1889-1900)", en Julio Pinto Vallejos, Trabajos y rebeldías en la pampa salitrera. El ciclo del salitre y la reconfiguración de las identidades populares (1850-1900), Santiago, Editorial, Universidad de Santiago, 1998, págs. 251-312; Sergio Grez Toso, La “cuestión social”. Ideas y debates precursores (1804-1902), Santiago, DIBAM - Centro de Investigaciones Diego Barros Arana, 1995.

18 Dr. J. Valdés Cange (Alejandro Venegas), Sinceridad. Chile íntimo en 1910, Santiago, Ediciones CESOC, 1998, págs. 223 y 224.

19 Salazar, La violencia política..., op. cit., pág. 72. Cursivas en el original.

20 Ibid.

21 Luis Alberto Romero, ¿Qué hacer con los pobres? Elites y sectores populares en Santiago de Chile 1840-1895, Santiago, Ariadna Ediciones, 2007, págs. 232 y 233.

22 Enrique Mac-Iver, "Discurso sobre la crisis moral de la República", en Grez, La “cuestión social”..., op. cit., págs. 519-528. 
23 Esta matanza obrera ha quedado inscrita en la memoria del pueblo chileno como un paradigma de la respuesta represiva del Estado y las clases dominantes ante las reivindicaciones de los trabajadores. El trabajo más completo sobre este tema es el libro de Eduardo Devés, Los que van a morir te saludan. Historia de una masacre: Escuela Santa María de Iquique, 1907, Santiago, Lom Ediciones, 2002, 4ª ed. Véase también, Varios autores, A 90 años de los sucesos de la Escuela Santa María de Iquique, Santiago, Lom Ediciones -DIBAM - Universidad Arturo Prat, 1998; Sergio Grez Toso, "La guerra preventiva: Santa María de Iquique. Las razones del poder", en Mapocho, N50, Santiago, segundo semestre de 2001, págs. 271-280; Pablo Artaza Barrios, Sergio González Miranda y Susana Jiles Castillo, A cien años de la masacre de Santa María de Iquique, Santiago, Lom Ediciones, 2009.

24 Romero, op. cit., pág. 234.

25 Véase, entre otros, Sergio Grez Toso, "El escarpado camino hacia la legislación social: debates, contradicciones y encrucijadas en el movimiento obrero y popular (Chile: 1901-1924)", en Cuadernos de Historia, №21, diciembre de 2001, págs. 119182, y “¿Autonomía o escudo protector? El movimiento obrero y popular y los mecanismos de conciliación y arbitraje (Chile, 1900-1924)", en Historia, vol. 35, Santiago, 2002, págs. 91-150; Julio Pinto V. y Verónica Valdivia O., ¿Revolución proletaria o querida chusma? Socialismo y Alessandrismo en la pugna por la politización pampina (1911-1932), Santiago, Lom Ediciones, 2001; Juan Carlos Yáñez Andrade, Estado, consenso y crisis social. El espacio público en Chile (1900-1920), Santiago, DIBAM - Centro de Investigaciones Diego Barros Arana, 2004, y La intervención social en Chile y el nacimiento de la sociedad salarial: 1907-1932, Santiago, RIL Editores, 2008.

26 Yáñez, La intervención social..., op. cit., págs. 307 y 308.

27 Enrique Fernández Darraz, Estado y sociedad en Chile, 1891-1931: el Estado Excluyente, la lógica estatal oligárquica y la formación de la sociedad, Santiago, Lom Ediciones, 2003.

28 Salazar, La violencia política..., op. cit., pág. 75-78.

29 Una extensa revisión de los acontecimientos del período 1925-1938 fue realizada por Gonzalo Vial, Historia de Chile (1891-1973), Santiago, Zig-Zag, vol. IV, 1996 y vol. V, 2001. Sobre la insurrección de 1931 de la marinería chilena, puede consultarse el prolijo acápite dedicado a estos sucesos en un libro sobre un tema más amplio escrito por Jorge Magasich, Los que dijeron "No". Historia de los marineros antigolpistas de 1973, Santiago, Lom Ediciones, 2008, vol. I, págs. 149-187.

30 Tomás Moulian, "Violencia, gradualismo y reformas en el desarrollo político chileno", en Adolfo Aldunate, Ángel Flisfich y Tomás Moulian, Estudios sobre el sistema de partidos en Chile, Santiago, FLACSO, 1985, págs. 13-68. La idea del "gran viraje" de la izquierda está expuesta más específicamente en págs. 49 y 50. Véase también del mismo autor, Fracturas. De Pedro Aguirre Cerda a Salvador Allende (1938-1973), Santiago, Lom Ediciones, 2006, págs. 19-142 y Contradicciones..., op. cit., págs. 27-39; Pedro Milos, Frente Popular en Chile. Su configuración: 1935-1938, Santiago, Lom Ediciones, 2008. 
31 Moulian, Contradicciones..., op. cit., pág. 40.

32 Carlos Hunneus, La Guerra Fría chilena: Gabriel González Videla y la Ley Maldita, Santiago, Random House Mondadori S. A., 2009.

33 Las reformas electorales de 1958 incluyeron la institución de una cédula única confeccionada por el Registro Electoral (que hizo casi imposible la compra de votos y el control electoral), la prohibición de los pactos a nivel provincial y la exigencia de pactos nacionales refrendados por las directivas máximas de los partidos, el castigo del cohecho con prisión inconmutable y la revalidación de los electores borrados por la Ley de Defensa de la Democracia. Moulian, Fracturas..., op. cit., págs. 169 y 170.

34 Ángela Vergara Marshall, "Represión y violencia estatal contra pobladores y mineros bajo el gobierno de la Democracia Cristiana: El Salvador (1966) y Puerto Montt (1969)" (inédito). Agradezco a su autora la gentileza de darme a conocer su manuscrito antes de publicarlo.

35 La experiencia del gobierno de la Unidad Popular ha sido objeto de numerosísimos estudios en todo el mundo. Ante la imposibilidad de citar siquiera una pequeña parte de dichos trabajos, nos limitamos a mencionar tres libros en los cuales el lector interesado en prolongar las reflexiones realizadas en este texto encontrará elementos interesantes: Tomás Moulian, Chile actual: anatomía de un mito, Santiago, Lom Ediciones, 1997, $1^{\text {a }}$ ed.; Luis Corvalán Márquez, Los partidos políticos y el golpe del 11 de septiembre, Santiago, Ediciones ChileAmérica Cesoc, 2000; Julio Pinto Vallejos (Coordinador-editor), Cuando hicimos Historia. La experiencia de la Unidad Popular, Santiago, Lom Ediciones, 2005.

36 El análisis global más incisivo sobre la sociedad chilena posdictatorial es la célebre obra de Tomás Moulian, Chile actual: anatomía de un mito, op. cit. Este libro, rápidamente convertido en un clásico, ha sido objeto de más de treinta reimpresiones.

37 Moulian, Fracturas ..., op. cit., pág. 272.

38 Ibid.

39 Según el informe 2009 del Programa de las Naciones Unidas para el Desarrollo (PNUD), la relación entre el ingreso per cápita del 10\% más rico de los hogares y el ingreso del 10\% más pobre de los hogares chilenos, es 26,2 veces. Traducido en los términos del Índice de Gini, que fluctúa entre 0 y 100, representando el 0 la línea hipotética de igualdad total y el 100 la desigualdad total, Chile se sitúa en un coeficiente de 52,2, uno de los peores del mundo. Programa de las Naciones Unidas para el Desarrollo (PNUD), Informe sobre Desarrollo Humano 2009. Superando barreras: Movilidad y desarrollo humanos, Madrid Mundi-Prensa Libros, 2009, pág. 209. La versión electrónica se encuentra disponible en: http://hdr.undp.org/en/media/HDR_2009_ES_Complete.pdf

40 Sebastián Piñera, el nuevo Presidente de la República elegido en enero de 2010, es dueño de una fortuna evaluada en unos 1.200 millones de dólares, lo que lo sitúa en el puesto 701 de las personas más ricas del mundo según la clasificación Forbes 2009. 
41 Sobre el carácter no democrático de los procesos constituyentes en la historia de Chile, véase, Sergio Grez Toso, "La ausencia de un poder constituyente democrático en la historia de Chile", en el libro de diversos autores, Asamblea Constituyente. Nueva Constitución, Santiago, Editorial Aún creemos en los sueños, 2009, págs. 35-58.

42 Luis Emilio Recabarren, Ricos y pobres a través de un siglo de vida republicana, Texto de una conferencia dictada en Rengo - Chile en la noche del 3 de septiembre de 1910, en ocasión del centenario de la independencia de Chile, Santiago, Imprenta New York, 1910. Este folleto se encuentra reproducido íntegramente en Cristián Gazmuri (editor), El Chile del Centenario, los ensayistas de la crisis, Santiago, Instituto de Historia Pontificia Universidad Católica de Chile, págs. 262-285. La versión electrónica está disponible en: http://www.marxists.org/espanol/recabarren/3ix-1910.htm

43 Poco después de presentada esta reflexión se produjo el terremoto y tsunami del 27 de febrero de 2010, que reveló con particular dramatismo la falta de cohesión social de la población chilena. La mayoría de los análisis críticos han explicado la participación de numerosas personas en los saqueos que se produjeron poco después de los movimientos sísmicos como la resultante directa de la gran desigualdad social y de la drástica aplicación modelo neoliberal, que ha promovido un individualismo exacerbado y ha destruido las redes asociativas populares, anulando de este modo los controles sociales más efectivos, resultantes del libre consentimiento. Véase, entre otros, el artículo de José Luis Ugarte, "Nuestros bárbaros", La Nación Domingo, Santiago, del 7 al 13 de marzo de 2010; y el excelente texto de los integrantes del Centro de Alerta e Investigadores del Observatorio Chileno de Políticas Educativas $(\mathrm{OPECH})$ - Universidad de Chile, Daniel Brzovic, Rodrigo Cornejo, Juan González, Rodrigo Sánchez y Mario Sobarzo, "Que se derrumben los sentidos comunes y se reconstruyan las comunidades: Reflexiones a partir del terremoto y maremoto en Chile", Santiago, 11 de marzo de 2010, en http://www.piensachile.com/content/view/6797/5/

44 Desde fines de la década de 1990 cada vez menos personas participan en las elecciones y $31 \%$ de los chilenos en edad de votar ni siquiera están inscritos en los registros electorales.

45 Una reflexión sobre los movimientos sociales en la actualidad en Pedro Armendaris, "Entrevista a Sergio Grez, ¿Hay movimiento popular en Chile?", en Punto Final, No691, Santiago, 7 al 20 de agosto de 2009, págs. 20 y 21. Versión electrónica disponible, ontre otros sitios web $\mathrm{http}: / /$ www.elclarin.cl/index.php?option=com_content\&task=view\&id=17865\&Item $\mathrm{id}=2729$ 


\section{El autor}

Sergio Grez Toso es Doctor en Historia de la Escuela de Altos Estudios en Ciencias Sociales de París, académico del Departamento de Ciencias Históricas de la Universidad de Chile y Coordinador del Doctorado en Historia de la Facultad de Filosofía y Humanidades de la misma casa de estudios.

Sus libros son: La 'cuestión social'en Chile. Ideas y debates precursores (18041903) (1995); De la 'regeneración del pueblo' a la huelga general. Génesis y evolución histórica del movimiento popular en Chile (1810-1890) (1998, $1^{\mathrm{a}} \mathrm{ed}$.); Los anarquistas y el movimiento obrero. La alborada de 'la Idea' en Chile (1893-1915) (2007); Magno Espinoza. La pasión por el comunismo libertario (2011); Historia del comunismo en Chile. La era de Recabarren (1912-1924) (2011). También es autor de numerosos artículos y capítulos de libro publicados en diversos países. 